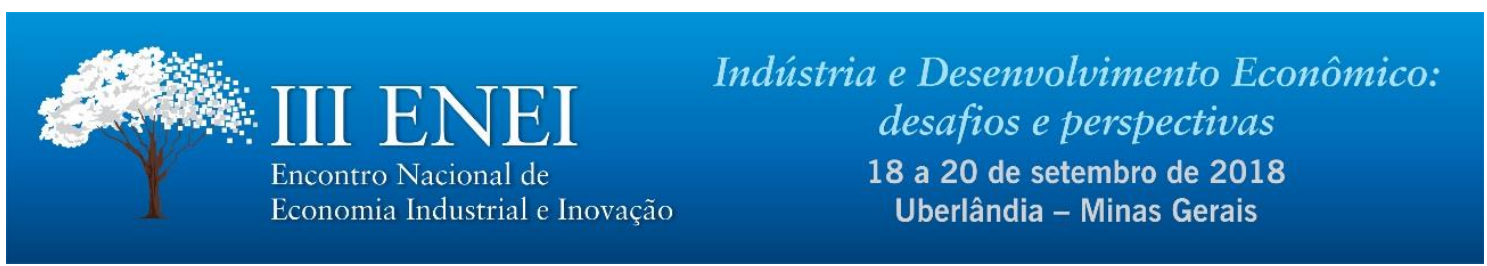

\title{
PRODUTIVIDADE E MERCADO DE TRABALHO DA INDÚSTRIA DE TRANSFORMAÇÃO BRASILEIRA: análise setorial frente à desaceleração econômica
}

Ademir Pedro Vilaça Júnior*

Resumo: Este trabalho procura analisar a evolução dos setores com maior potencial de inovações intersetoriais no Brasil traçando paralelos com a indústria de transformação. Do ponto de vista teórico, partimos da concepção de subdesenvolvimento de Celso Furtado para traçar considerações sobre especificidades persistentes na dinâmica de acumulação de capital em países periféricos. O reconhecimento da heterogeneidade estrutural da economia aumenta a importância de setores capazes de difundir o progresso tecnológico para o resto da economia. Sob este panorama, fazemos uma análise sobre indicadores de produtividade e emprego para a indústria brasileira. Concluímos que esses segmentos têm participação significativa na estrutura produtiva nacional, mas foram afetados negativamente no período recente. Nesse sentido, um processo de crescimento sustentado está relacionado com estímulo direcionado aos segmentos com maior potencial de contornar os gargalos persistentes da estrutura produtiva nacional

Palavras-chave: heterogeneidade produtiva; mudança estrutural, crescimento.

Abstract: This paper strives to analyze the evolution of sectors with greater potential of generating intersectorial innovations in Brazil. Departing from the Celso Furtado's conception of underdevelopment, we identify persistent specificities on the capital accumulation dynamics in peripheral countries. The acknowledgment of the structural heterogeneity in these economies enhances the importance of sectors able to propagate the technological improvement to the economic structure. In this context, we analyze the evolution of productivity indexes and the labor market of Brazilian manufacturing industry. We conclude that these sectors have significant participation in the productive matrix, but were jeopardized in the recent period. In this way, a sustained growth process is related to oriented actions to enhance the participation of sector with greater potential to overcome persistent bottlenecks of the productive structure.

Keywords: productive heterogeneity; structural change, growth.

Classificação JEL: O14; L16; L60

Área temática ABEIN:

1.1 Dinâmicas industriais setoriais e dos sistemas de produção

1.3 Crescimento, produtividade e competitividade

\footnotetext{
- Mestre em Economia do Desenvolvimento pela UFRGS e Coordenador-Geral substituto da Coordenaçãogeral de Estudos e Pesquisas, Avalição, Tecnologia e Inovação da Superintendência de Desenvolvimento do Nordeste - SUDENE
} 


\section{Introdução}

A indústria sempre foi um tema recorrente em economia. Seu dinamismo inovador e a capacidade de incorporar mão de obra com baixa produtividade induzem o crescimento da produtividade e da renda. O trabalho seminal de Kaldor (1966) estabeleceu a concepção de que a indústria tem especificidades que afetam o crescimento em processos cumulativos e pathdependents. Economias estáticas e dinâmicas de escala aumentam a produtividade, quebrando a ideia de retornos constantes que prevalece nas concepções de mainstream. Ainda hoje a indústria é o principal lócus de geração e difusão de inovações e produz bens com maior elasticidade renda e menor elasticidade preço das exportações (FEIJÓ \& LAMONICA, 2013; JAYME JR \& RESENDE 2009).

O estruturalismo latino-americano ressalta a importância da indústria e busca analisar a dinâmica de crescimento dos países subdesenvolvidos com um arcabouço teórico que enfatiza as particularidades e gargalos que condicionam o desenvolvimento da periferia. Furtado (1961) destaca que a especialização produtiva é uma característica marcante desses países, assim como heterogeneidade estrutural, definida como expressiva diferença de produtividade entre os segmentos (PINTO, 1971) ${ }^{1}$.

Essas características têm impactos sobre a estrutura social, já que determinam o padrão ocupacional e de distribuição de renda (RODRIGUEZ, 2009). Outro aspecto central da abordagem estruturalista é o excesso estrutural de mão de obra, que diminui o poder de barganha dos trabalhadores por aumentos salariais (FURTADO, 1961; OLIVEIRA, 1981). Além disso, destaca-se a importância da restrição externa ao crescimento, consubstanciada na recorrente constrição na capacidade de importar, que acaba dificultando a acumulação de capital.

Assim, conforma-se uma estrutura produtiva com expressivos diferenciais de produtividade e um grande contingente de empregos com baixa produtividade. A superação do subdesenvolvimento é entendida como a incorporação da mão de obra de baixa produtividade em setores mais produtivos (FURTADO, 1961; RODRIGUEZ, 2009).

Nessa perspectiva, o crescimento do setor industrial é fundamental para absorver o excedente de mão de obra, melhorar a produtividade (devido ao maior dinamismo inovador) e a distribuição da renda (por causa da maior remuneração desses segmentos). A industrialização brasileira foi organizada sob esses paradigmas, buscando diversificar a estrutura produtiva para superar o subdesenvolvimento (CANO, 2008).

Entretanto, a experiência mostra que a diversificação da matriz produtiva é condição necessária, mas não suficiente para superar a especialização e a heterogeneidade. Houve adensamento do tecido industrial e diversificação da produção, mas a dependência tecnológica se mantém, contribuindo para o atraso em relação ao centro (FAJNZYLBER, 1976; HOLLAND \& PORCILLE, 2005; OLIVEIRA \& FEIJÓ 2011).

Tendo em vista o recorrente debate sobre a desindustrialização brasileira, esse artigo tem o intuito de mostrar a evolução da indústria de transformação brasileira com foco em produtividade e emprego $^{2}$. O trabalho contribui para o debate na medida em que atualiza os dados para a indústria fazendo um corte setorial que busca entender as particularidades da atividade produtiva e avaliar segmentos com maior potencial de promover o desenvolvimento da matriz produtiva brasileira.

Nesse sentido, o artigo se subdivide em quatro seções além dessa introdução. A segunda seção detalha o marco teórico e tece algumas considerações sobre a conjuntura econômica para a

\footnotetext{
${ }^{1}$ A heterogeneidade estrutural que caracteriza a periferia é definida como a existência de grandes diferenças nos níveis de produtividade do trabalho entre os setores da economia e dentro de cada setor. Essas diferenças são suficientes para segmentar claramente o sistema produtivo e o mercado de trabalho em diversas frações, onde as condições tecnológicas e de remuneração são bastante assimétricas (CIMOLI et al. 2005).

2 Uma análise sobre o desempenho externo é fundamental para traçar um panorama completo da indústria, mas não foi possível no espaço deste artigo.
} 
indústria. A terceira seção apresenta dados do mercado de trabalho enquanto a quarta apresenta indicadores de produtividade. Por fim, são apresentadas as considerações finais.

\section{Indústria, dinamismo tecnológico e crescimento}

O progresso técnico aumentou a complexidade da estrutura industrial, gerando dinâmicas específicas de acumulação nos segmentos produtivos, o que acentuou a importância da indústria. Alcorta (1994) mostra que as novas tecnologias tiveram impactos ambíguos, gerando flexibilização em graus distintos na matriz industrial. Malerba \& Nelson (2011) reafirmam a importância das especificidades setoriais relacionadas à estruturação das cadeias produtivas (elos com fornecedores e usuários, fontes de financiamento) e à forma como o progresso técnico é incorporado e difundido (bases técnicas específicas, caráter tácito do aprendizado e fontes de conhecimento).

Nessa mesma linha, Dosi (1984) e Dosi et al. (1990) defendem a ideia de que as trajetórias tecnológicas (específicas de cada setor) condicionam os ganhos de produtividade. Essas trajetórias estão ligadas às capacitações tecnológicas das firmas, entendidas como diferenciais competitivos na medida em que são a base para a apreensão e expansão do progresso técnico e, consequentemente, da capacidade de acumulação de capital.

Dentro dessa perspectiva, Cimoli et al. (2005) defendem que o estímulo ao crescimento deve ser baseado na expansão de atividades tecnologicamente dinâmicas, que apresentam duas características básicas: taxas de crescimento da produtividade superiores à média da indústria e maior possibilidade de difusão intersetorial do progresso técnico, ou seja, maior "penetrabilidade" da inovação.

O dinamismo é reflexo da conjunção de maiores incrementos da produtividade e propagação desses ganhos. A difusão diminui a heterogeneidade estrutural e aumenta produtividade sistêmica. Além disso, uma vez que setores tecnologicamente dinâmicos precisam de maior qualificação da mão de obra, a expansão gera empregos com maior remuneração, aumentando o poder de compra em um ciclo virtuoso de expansão da renda. Assim, para países com heterogeneidade estrutural, os setores "difusores do conhecimento" são fundamentais para alavancar o desenvolvimento.

A propagação aumenta a produtividade setorial ao mesmo tempo em que diminui a heterogeneidade estrutural. Para o Brasil, os trabalhos Carvalho \& Kupfer (2007) e de Gramkow (2011) mostram que a heterogeneidade ainda é uma característica marcante da estrutura produtiva nacional.

Jayme Jr \& Resende (2009) ressaltam que os segmentos tecnologicamente dinâmicos apresentam maior elasticidade-renda e menor elasticidade-preço das exportações. Sob essa perspectiva, a inserção internacional é importante por dois aspectos. Por um lado, tendo em vista que a competição externa pressupõe desenvolvimento tecnológico, há constante estímulo à inovação. Por outro, o mercado externo garante a continuidade da acumulação de capital e possibilita a incorporação de bens de capital com maior conteúdo tecnológico.

Além disso, como esses setores apresentam maiores taxas de crescimento no comércio internacional (BRITTO, 2013; CIMOLI et al 2005; LALL, 2000), sua expansão também atenua a restrição externa, característica central e contemporânea do subdesenvolvimento (GOUVÊA \& LIMA, 2011). Assim, é importante ter uma estrutura produtiva intensiva em tecnologia na medida em que ela oferece melhores perspectivas de crescimento, como indica Lall (2000):

"They (Technology-intensive structures) have greater potential for further learning because they offer more scope for applying new scientific knowledge. They have larger spillover effects in terms of creating new skills and generic knowledge that can be used in other activities. Simple technologies, by contrast, tend to have slower growing markets, more limited learning potential, smaller scope for 
technological upgrading and less spillover to other activities" (p. 339-340).

Em resumo, os padrões de especialização produtiva e o perfil exportador geram implicações fundamentais no que se refere à dinâmica de crescimento de longo prazo, posto que os setores estão associados a diferentes elasticidades-renda da demanda por exportações, graus distintos de retornos de escala e diversas possibilidades de inovação tecnológica e aprendizado.

Considerando a dinâmica de acumulação de capital em nível global, Cimoli et al.(2005) apresentam o conceito de hiato (brecha) tecnológico, entendido como a diferencial de produtividade de um país em relação aos países com maior nível de produtividade. Este conceito está relacionado com a heterogeneidade externa de uma economia.

Assim, apresenta-se um problema adicional no âmbito dos países subdesenvolvidos. Além das divergências setoriais internas, há um expressivo diferencial em relação às economias mais dinâmicas, de modo que o esforço deve ser direcionado para diminuir as discrepâncias de produtividade tanto no âmbito interno quanto no externo. Sob esta perspectiva, setores com maior potencial de difusão de inovações adquirem caráter central, pois representam a possibilidade de aumentar a produtividade sistêmica e atenuar a distância em relação ao centro.

De acordo com Porcile et al. (2010), um dos aspectos da brecha tecnológica está ligado à incapacidade dos países periféricos em incorporar e difundir o progresso técnico na mesma velocidade dos países centrais, acentuando o hiato entre essas economias. Consequentemente (e cumulativamente) a periferia tem menor nível de produtividade em relação ao centro (heterogeneidade externa), perpetuando a especialização produtiva, visto que a periferia mantém sua inserção internacional baseada em bens de menor produtividade relativa e baixa elasticidaderenda. A dificuldade na absorção e, principalmente, na difusão das inovações perpetua a heterogeneidade e a especialização. A heterogeneidade (interna e externa) só pode ser superada a partir do crescimento da produtividade da economia, diminuindo a discrepância interna e em relação ao centro ${ }^{3}$.

Entretanto, a efetiva relevância desses setores dinâmicos só pode ser apreendida a partir de um corte metodológico que capte suas particularidades. Para entender as especificidades da acumulação de capital na indústria, Pavitt (1984) criou uma tipologia para segmentar a atividade industrial, denotando que o incremento de produtividade segue características setoriais específicas que tendem a se perpetuar, em um efeito de lock-in que condiciona o crescimento.

A tipologia de Pavitt (1984) apresenta três categorias de firmas: baseadas em ciência, dominadas por fornecedores e intensivas em produção (que se subdivide em intensivas em escala e com fornecedores especializados). A origem e forma predominante da inovação (produto ou processo) estão relacionadas com a natureza do processo produtivo, sendo que a estrutura de mercado, gastos em inovação e a organização da cadeia são determinantes fundamentais da acumulação de capital dos setores.

A partir dessas considerações, a OCDE incorporou a classificação de Lall (2000) que separa os setores de acordo com a complexidade técnica de seus processos produtivos, associada com o grau de conhecimento tecnológico incorporado ao produto e com a apropriabilidade da técnica, ou seja, a capacidade de manutenção do monopólio tecnológico. Os setores de baixa intensidade tecnológica têm estruturas de produção facilmente copiáveis e difundidas, enquanto os setores mais intensivos em tecnologia apresentam especificidades que inibem sua cópia e difusão. $\mathrm{O}$ conhecimento (especialmente o tácito) adquire importância crescente pois é um dos principais eixos de diferenciação dos processos de produção, influenciando as estruturas de mercado e a inserção comercial dos produtos.

\footnotetext{
${ }^{3}$ Como a difusão de novas tecnologias não ocorre imediatamente, países com maior capacidade inovativa obtêm vantagens no comércio. Como os setores dinâmicos têm maior potencial para desenvolver novas tecnologias, há uma tendência a divergência de renda per capita entre países (Cimoli et al., 2005).
} 
É importante ressaltar que a intensidade tecnológica não está necessariamente relacionada com a quantidade de capital utilizada, mas com a capacidade diferenciação do processo produtivo. O progresso técnico possibilitou que indústrias de baixa complexidade tecnológica (i.e. têxteis; calçados; móveis) adotassem métodos de produção capital-intensivos com maquinização e automatização. Ainda que relevante, essa modificação não alterou estruturalmente a intensidade tecnológica dessas indústrias, visto que a modernização é decorrente da aplicação de inovações geradas em outros segmentos produtivos. Em outras palavras, a capacidade de difusão intersetorial de inovações alavancou as possibilidades de acumulação em segmentos que tinham poucas perspectivas de avanço tecnológico.

É exatamente este fenômeno que justifica o estudo da participação dos setores tecnologicamente dinâmicos no tecido industrial. Como alguns setores têm maior capacidade de difundir inovações, seu desenvolvimento aumenta as produtividades intra e intersetoriais. A possibilidade de transmissão de inovações é fundamental para garantir o crescimento da produtividade e torna-se ainda mais relevante em países com heterogeneidade produtiva.

Com o intuito de avançar nessa temática e analisando prioritariamente países subdesenvolvidos com forte heterogeneidade estrutural, Cimoli et al. (2005) estabeleceram uma estratificação que tem como parâmetro a capacidade dos setores de produzir transbordamentos. Os estratos considerados são: atividades baseadas em Recursos Naturais; intensivas em Trabalho; e difusoras do conhecimento ${ }^{4}$.

Acreditamos que esse recorte apresenta um avanço na medida em que considera a heterogeneidade estrutural como problema fundamental do subdesenvolvimento e consideramos que a análise sobre a evolução dos setores que podem atenuar a heterogeneidade é pré-requisito para superação do subdesenvolvimento. Assim, este trabalho busca avaliar a relevância destes segmentos e faz parte de um esforço maior de mapeamento da indústria. Seguimos a Classificação Nacional de Atividades Econômicas (CNAE). Os setores foram selecionados no nível de divisões (2 dígitos) para facilitar a exposição.

Com relação ao mercado de trabalho, são analisados dados de emprego a partir da Relação Anual de Informações Sociais (RAIS), mostrando a evolução dos setores e sua relação com a indústria de transformação (IT). Apresentamos dados do número total de trabalhadores, faixas de remuneração e salário real médio.

Para a produtividade do trabalho, utilizamos dados da Pesquisa Industrial Anual (PIA). O objetivo é avaliar o comportamento desses setores desde a crise econômica mundial até o período recente. Assim é possível dimensionar o grau de heterogeneidade existente na indústria brasileira e seu comportamento no ciclo recessivo internacional e na posterior estagnação econômica nacional.

Antes de analisar os dados, é importante ressaltar que a partir de 2008 a indústria foi beneficiada por uma série de subsídios, que surgiram incialmente como medida de estímulo para o setor automotivo tendo em vista a crise econômica mundial de 2008. Essa política foi estendida em 2009 para setores de bens de consumo duráveis, materiais de construção, equipamentos, móveis e alimentos 5 .

\footnotetext{
4 Para os recursos naturais foram considerados os seguintes setores: "produtos alimentícios" (10), "bebidas" (11), "produtos do fumo" (12), "celulose e produtos de papel” (17), "coque, derivados do petróleo e biocombustível” (19), "produtos químicos" (20), "minerais não metálicos" (22) e "metalurgia" (24).

Para intensivos em trabalho: "têxteis" (13), "vestuário e acessórios" (14), "couro e artigos de viagem" (15), "produtos de madeira" (16), "impressão, reprodução e gravações” (18), "borracha e material plástico" (22), "móveis” (31) e "produtos diversos".

Para os difusores: "farmoquímicos e farmacêuticos" (21), "produtos de metal exceto máquinas e equipamentos" (25), "equipamentos de informática, eletrônicos e ópticos" (26), "máquinas, aparelhos e materiais elétricos" (27), "máquinas e equipamentos" (28); "veículos automotores" (29), "outros equipamentos de transporte" (30) e "manutenção, reparação e instalação de máquinas e equipamentos" (33).

${ }^{5}$ Uma síntese dessas considerações pode ser encontrada em Carvalho (2018).
} 
Em 2011 o foi criado o Plano Brasil Maior, que ampliou medias tributárias de desoneração para incentivar setores produtivos. O plano previa a redução do IPI sobre máquinas e equipamentos, materiais de construção, caminhões e veículos, além da desoneração da folha de pagamentos.

A desoneração substituiu a base de cálculo da Contribuição Previdenciária Patronal de $20 \%$ sobre a folha de salários para entre $1 \%$ e $2 \%$ sobre o faturamento da empresa. O objetivo da política era manter empregos e elevar a competitividade em setores intensivos em trabalho. Inicialmente aplicada para 4 setores e de caráter temporário, a política foi estendida para 56 setores e tornou-se permanente. Na medida em que foi expandida para diversos setores, ela não pode ser caracterizada como uma política industrial direcionada. Ao contrário, teve caráter horizontal e acabou beneficiando segmentos com maior quantidade de empregos e salários mais altos.

Como ressaltado por Carvalho (2018), Afonso e Pinto (2014) fizeram uma análise da composição setorial da política de desoneração da folha de pagamentos. O custo anual com as renúncias foi de $\mathrm{R} \$ 45$ bilhões em 2012, $\mathrm{R} \$ 74,8$ bilhões em 2013 e 101,3 bilhões em 2014. Os autores mostram que a indústria de transformação respondeu por $44,8 \%$ do valor renunciado, seguido pelos setores de serviço, com 42,8\% e construção civil, com 11,8\%. Dessa forma, o período foi marcado por forte desoneração para a indústria.

Entretanto, destaca-se que a política não estabeleceu contrapartidas claras por parte do empresariado. Como representava uma diminuição dos custos para as desonerações se refletiram em recomposição das margens de lucro da indústria, sem estímulo claro ao investimento. O desaquecimento da demanda que marca o período foi fator central para inibir novos investimentos. Isso porque ainda que a margem de lucro tenha aumentado, a queda da demanda diminuiu o lucro total das firmas. Em um cenário de queda das vendas e da capacidade utilizada, não havia estímulo para realização de novos investimentos.

Essa conjuntura foi diretamente influenciada pelo comportamento da taxa de câmbio, que teve tendência à valorização da taxa de câmbio, como mostra o gráfico abaixo. Fica clara a forte tendência de valorização, com o índice acima de 100 para a maior parte do período, com aceleração da apreciação a partir de meados de 2014 e posterior reversão em meados de 2016.

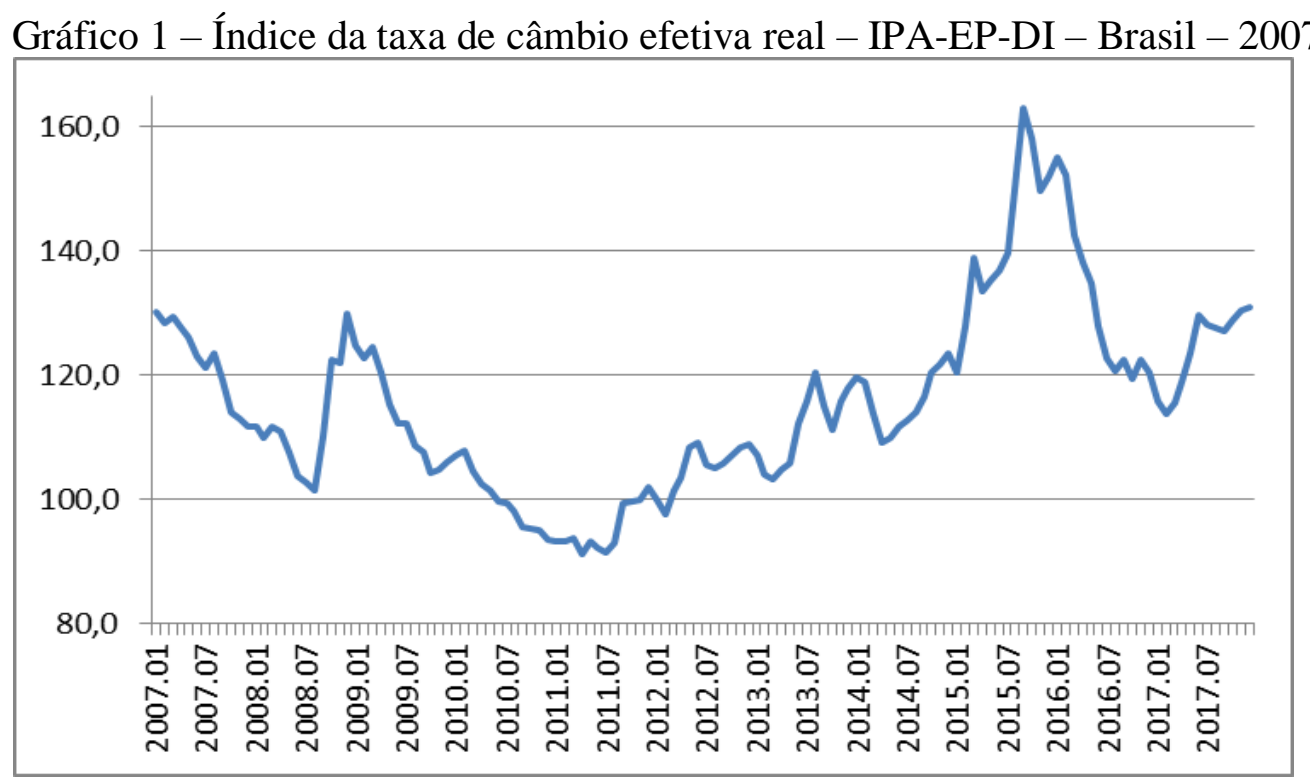

Fonte: IPEAdata

Essa tendência é fruto da grande instabilidade monetária decorrente da crise econômica de 2008. Com o objetivo de estimular a economia, os EUA e Europa adotaram políticas agressivas de expansão monetária, o Quantitative Easing, aumentando expressivamente a oferta de dólares na 
economia $^{6}$. Ressalta-se que a crise política também afeta diretamente o câmbio, uma vez que a instabilidade política se reflete em valorização da moeda.

Esse panorama é importante para compreender melhor a conjuntura econômica no período de análise desse artigo, com influências conflitantes. Se por um lado a indústria de transformação se beneficiou de um programa agressivo de desoneração fiscal que aumentou a margem de lucro, de outro, o desaquecimento da demanda e o aumento da concorrência externa, contribuíram par deprimir a atividade industrial. Tendo em vista a coexistência dessas pressões, a seguir apresentamos uma análise que busca compreender o desempenho da indústria de transformação brasileira no período recente.

\section{Evolução do emprego}

Essa seção procura descrever a dinâmica do mercado de trabalho considerando o recorte setorial adotado. As informações foram retiradas da Relação Anual de Informações Sociais (RAIS), que contém dados sobre empregos formais. As bases estão disponíveis até 2016. Ressalta-se que como os dados da PIA sobre emprego são amostrais, ao passo que os dados da RAIS são fornecidos obrigatoriamente por todas as empresas. Nesse sentido, é possível que existam discrepâncias com relação ao número de trabalhadores e à dinâmica de cada setor.

São apresentados dados sobre evolução do emprego total, salário real médio e distribuição do emprego por faixas de remuneração. Fazemos comparações entre os recortes selecionados e com o conjunto da indústria de transformação para identificar eventuais especificidades setoriais.

Entre 2007 e 2016 o emprego na indústria de transformação avançou 1,1\%, totalizando 6,7 milhões de empregados, enquanto o emprego total no Brasil teve crescimento de $22,5 \%$. Assim, a participação da indústria de transformação caiu de $18 \%$ para $14,7 \%$ do emprego nacional no período.

Dentro do recorte analisado, os setores de recursos naturais cresceram $11 \%$ enquanto os intensivos em trabalho e os difusores caíram $7 \%$ e $2,5 \%$, respectivamente. Dessa forma, recursos naturais passaram a responder por $41 \%$ dos trabalhadores da indústria, setores intensivos em trabalho por $32 \%$ e os difusores por $26 \%$. Esses dados corroboram as análises apresentadas, com perda de participação dos segmentos com maior potencial de inovações interssetoriais.

Ainda que a dinâmica de emprego não tenha sido muito favorável para a indústria e mais especificamente para os difusores, o comportamento do salário real seguiu padrão distinto, com clara tendência de ascensão para todos os segmentos analisados. O gráfico abaixo apresenta os dados por setor. Todos os valores foram deflacionados pelo IPCA.

\footnotetext{
6 Para atenuar esses efeitos, o Brasil implementou alíquotas de IOF para conter a sobrevalorização da moeda. Entretanto, ainda que elas conseguissem diminuir a volatilidade do dólar, essas medidas não foram suficientes para influenciar o desempenho exportador do país (CARVALHO, 2018).
} 
Gráfico 2 - Salário Real - setores selecionados - 2007-2016 - R\$

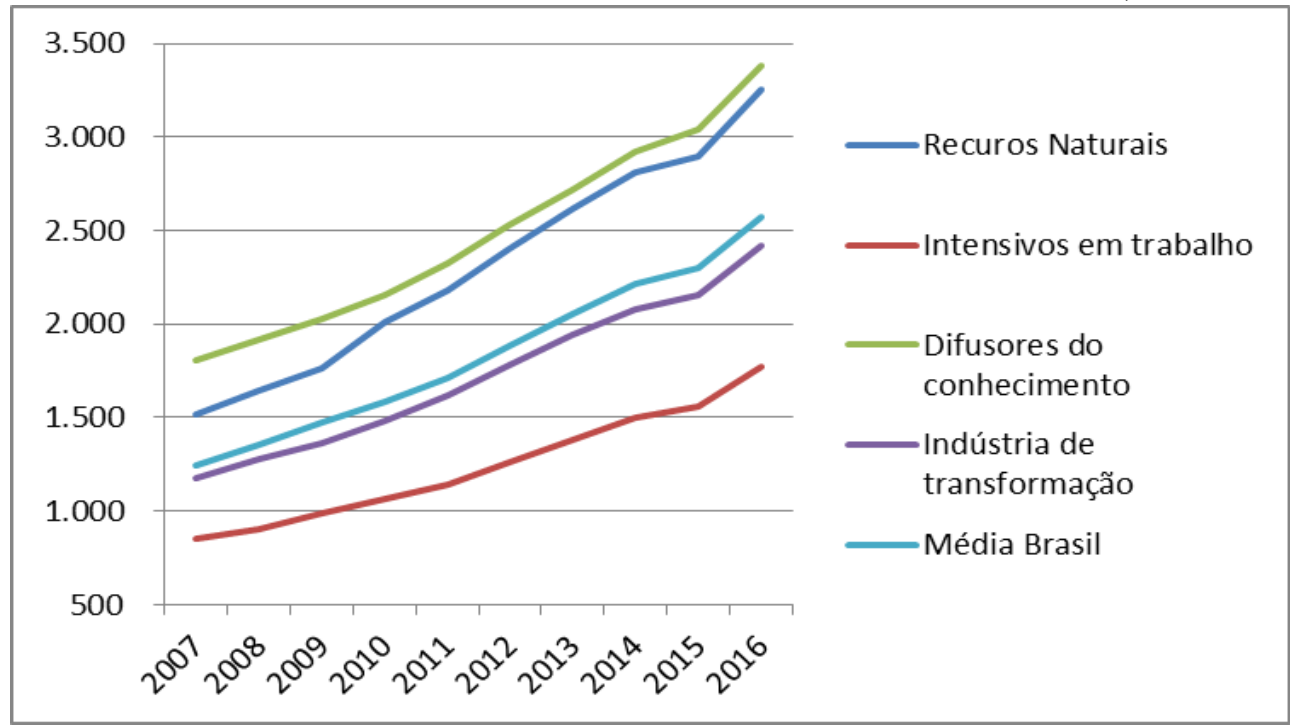

Fonte: Elaboração a partir da RAIS

Mais uma vez fica clara a heterogeneidade que marca a estrutura produtiva brasileira e se reflete diretamente no padrão de remuneração da economia, como preconizado pela literatura estruturalista. O setor que se destaca com maior remuneração é o dos difusores do conhecimento, $4 \%$ acima dos setores de recursos naturais, $91 \%$ acima dos intensivos em trabalho, $40 \%$ maior do que a indústria de transformação e $31 \%$ maior que a média nacional. Isso corrobora a concepção de maior remuneração de segmentos tecnologicamente dinâmicos.

É interessante notar que o salário médio do Brasil é maior do que o salário industrial. Esse fato se deve à alta remuneração dos setores ligados à administração pública e alguns serviços mais complexos, como os financeiros.

Os setores de recursos naturais estão crescendo mais rápido do que os intensivos em trabalho, de modo que a distância dos recursos naturais em relação ao salário médio da indústria de transformação se ampliou mais do que a aproximação para os setores intensivos em trabalho. Assim, também no âmbito do salário real nota-se que a convergência é parcial. Ou seja, os setores intensivos em trabalho e difusores tiveram queda do pessoal ocupado acompanhada por menor crescimento do salário. A conjunção desses fatores representa indícios de especialização da indústria de transformação nos setores intensivos em recursos naturais.

Esses movimentos têm impacto direto na massa salarial, entendida como o total de recursos que foi transferido aos trabalhadores. Enquanto a massa total brasileira cresceu $152 \%$ entre 2007 e 2016, a indústria de transformação cresceu 107\%. Mais uma vez houve menor crescimento dos difusores (85\%), enquanto recursos naturais avançaram 134\% e intensivos em trabalho 99\%. Para complementar a análise, o gráfico abaixo mostra a distribuição de trabalhadores por faixa salarial. 


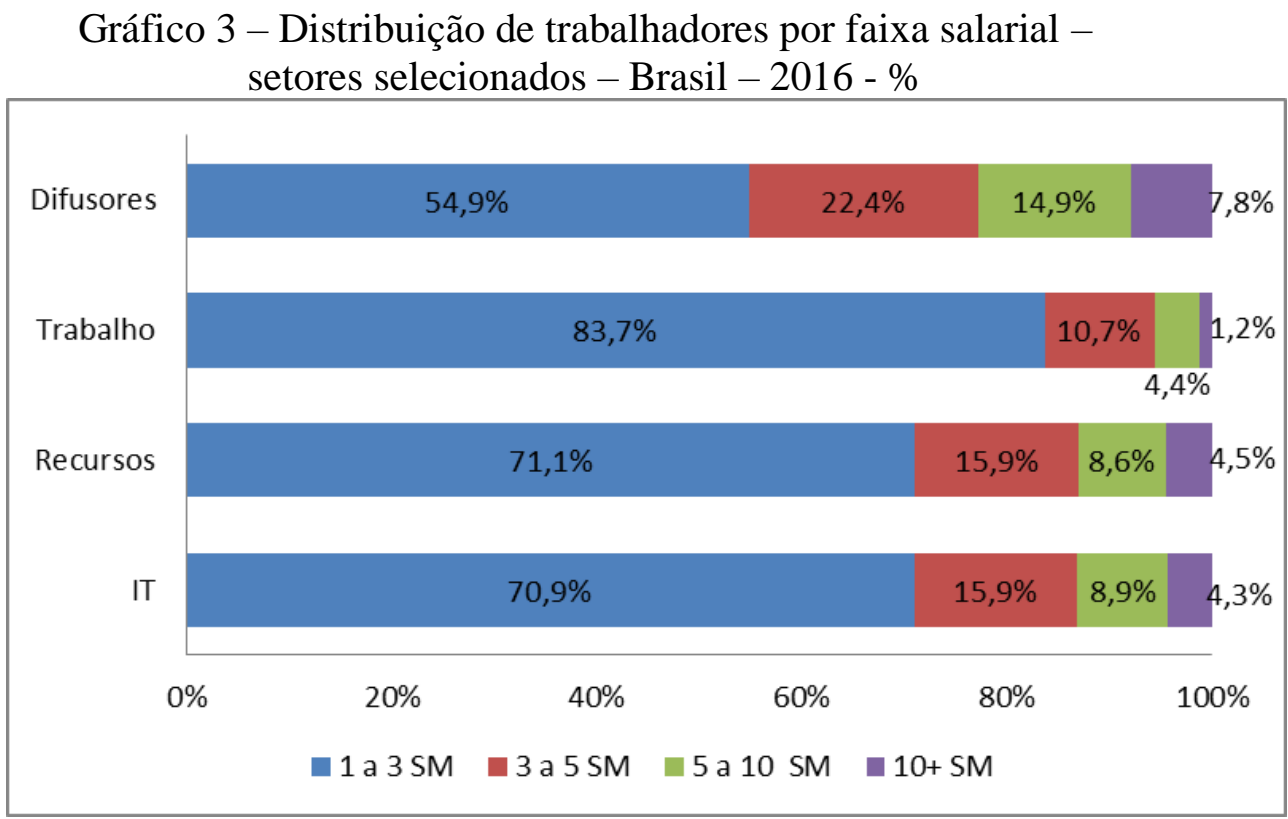

Fonte: Elaboração a partir da RAIS

Fica claro o melhor padrão dos difusores. Ainda que parte significativa dos trabalhadores tenha remuneração de até três salários mínimos $(\mathrm{SM})$, o percentual está bem abaixo dos outros setores. Inversamente, o percentual de trabalhadores nas faixas superiores é muito maior, atingindo o dobro em alguns casos.

Em suma, os dados do mercado de trabalho corroboram a hipótese estruturalista de alta segmentação, com forte diferencial de remuneração entre os segmentos. Com relação à evolução no período recente, a indústria apresentou crescimento menor do que o total da economia, diminuindo a participação no emprego. Desagregando setorialmente, os difusores tiveram menor crescimento, diminuindo sua parcela tanto no total de empregos quanto na massa salarial.

Também no âmbito do emprego os setores de recursos naturais se destacam como motores do crescimento. Dessa forma, o padrão do mercado de trabalho da indústria de transformação está alinhado com as características observadas nos indicadores de produtividade, com tendências à especialização nos segmentos de recursos naturais, que têm menor potencial de gerar inovações para outros setores produtivos. Feitas essas considerações, a seguir apresentamos os dados para a produtividade do trabalho no período destacado.

\section{Produtividade do trabalho na indústria de transformação}

A Pesquisa Industrial Anual (PIA) é uma das principais fontes de dados oficiais para análise de produtividade setorial. Para tanto, utilizamos 2 indicadores: o primeiro é a densidade industrial, dada pelo Valor da Transformação Industrial (VTI) por trabalhador (PO), que mede a produtividade do trabalho por setor. Além disso, seguindo o trabalho de Oliveira e Feijó (2011), utilizamos a razão entre o Valor Bruto da Produção Industrial (VBPI) e o VTI, ou "índice de agregação de valor", que mede a capacidade de incorporação de valor.

Para complementar a análise, apresentamos dados sobre componentes de custos das empresas com o intuito de identificar quais as principais pressões observadas. Dessa forma, procuramos traçar um panorama sobre da evolução da produtividade e principais obstáculos para o crescimento da indústria.

Ressalta-se que todos os valores foram deflacionados pelo IPA-OG, seguindo a metodologia utilizada por Oliveira e Feijó (2011) e Britto (2013). O primeiro indicador é o de densidade industrial, dado pela razão entre VTI e pessoal ocupado (PO), que serve como proxy da 
produtividade do trabalho. A análise do indicador é complementada pela evolução de cada um dos seus componentes para avaliar o comportamento da produtividade entre os setores.

Antes de apresentar o indicador, é importante fazer considerações sobre seus componentes. No âmbito do VTI, o crescimento foi puxado pelos segmentos de recursos naturais, que avançaram $83 \%$ no período, ao passo que os intensivos em trabalho avançaram $73 \%$ e os difusores $49 \%$. Paralelamente, no que se refere à mão de obra ocupada, os intensivos em recursos aumentaram $21 \%$ enquanto os intensivos em trabalho diminuíram $1 \%$ e os difusores cresceram $4 \%$ e.

Dessa forma, os setores intensivos em trabalho tiveram crescimento "espúrio" da produtividade do trabalho, ou seja, um incremento do VTI acompanhado por queda da mão de obra ocupada. Por outro lado, os setores de recursos naturais e difusores conseguiram um incremento concomitante do VTI e do pessoal ocupado, caracterizando um processo virtuoso de expansão. Destaca-se que esse movimento foi muito mais expressivo no setor de recursos naturais.

Os dados são apresentados no gráfico 1. Inicialmente, ficam claras duas características centrais. A tendência de crescimento, ainda que fraca, para todos os setores e a clara discrepância de produtividade entre os segmentos produtivos.

Gráfico 4 - Densidade Industrial (VTI/PO) - setores selecionados - Brasil 2007-2015 - R \$ mil/trabalhador

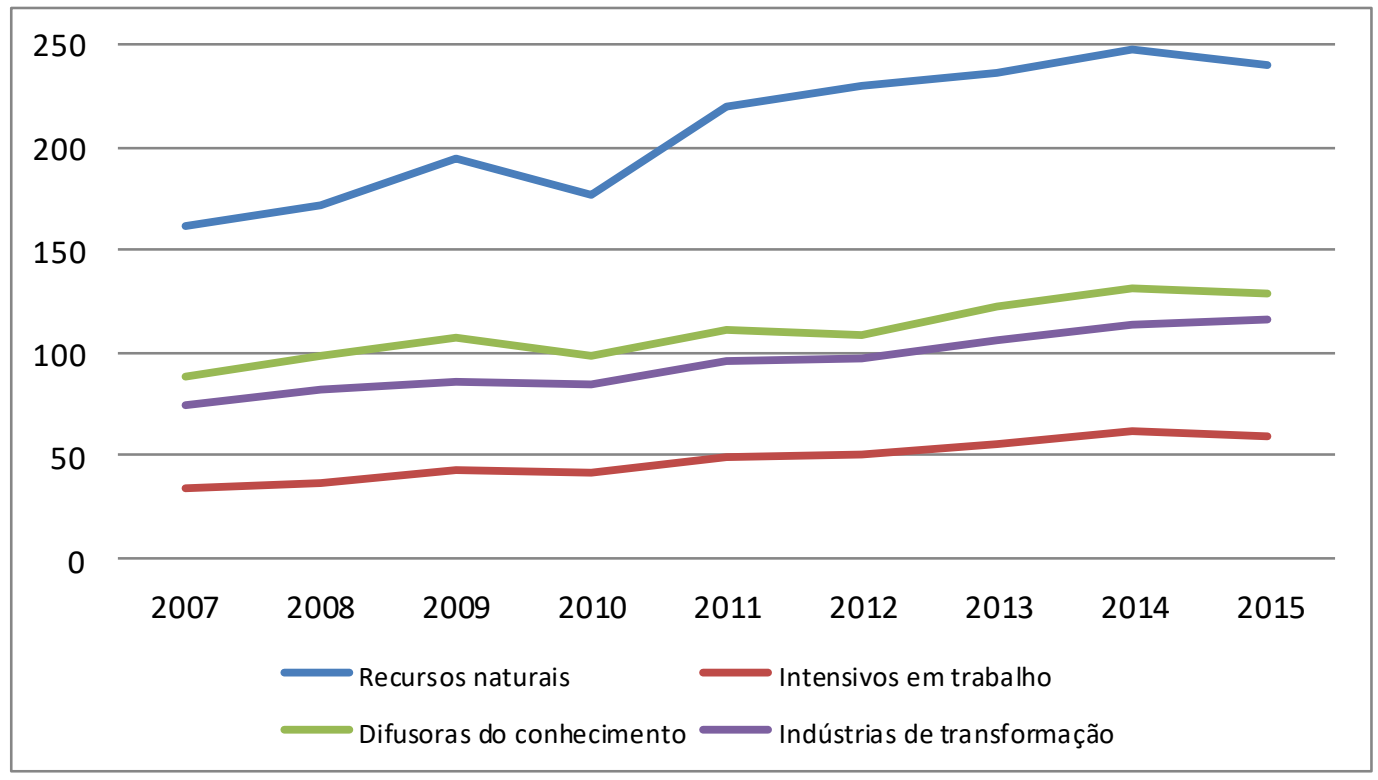

Fonte: Elaboração a partir da PIA

O gráfico também mostra a resposta da indústria em relação à crise econômica mundial. Os setores de recursos naturais e difusores de conhecimento tiveram queda no indicador em 2010, já superada no ano seguinte. Esse movimento foi um reflexo da queda do VTI acompanhado por crescimento do emprego, o que mostra que mesmo em contexto externo adverso houve expansão do emprego.

O incremento da produtividade foi puxado pelos setores intensivos em trabalho, com expansão de $75 \%$. Recursos naturais tiveram expansão de $48 \%$ enquanto os difusores avançaram $45 \%$. A média para a indústria de transformação foi de $55 \%$. Assim, para a análise de produtividade (VTI/PO), houve convergência parcial entre setores da indústria, com crescimento mais expressivo do setor com menor produtividade. Entretanto, é importante analisar o comportamento dos dois componentes do indicador para compreender a dinâmica desses movimentos. 
Mesmo em um contexto de perda de participação da indústria na matriz produtiva nacional e forte concorrência externa, os setores industriais, de modo geral, conseguiram um resultado positivo no período de análise.

Para analisar o grau de heterogeneidade da indústria de transformação brasileira, é importante apresentar os níveis de produtividade para cada setor. Os setores de recursos naturais têm o dobro da produtividade da indústria de transformação (IT), ao passo que os difusores têm produtividade $10 \%$ maior e os intensivos em trabalho tem metade da produtividade média da indústria brasileira. Considerando a brecha tecnológica dentro da indústria, entendida como a diferença de produtividade de dado setor em relação ao segmento mais produtivo, os difusores têm produtividade igual à metade da observada em recursos naturais ao passo que os setores de trabalho atingem um quarto desse valor.

O indicador de produtividade do trabalho corrobora a concepção de heterogeneidade da estrutura produtiva, com forte discrepância setorial. Tendo em vista que a acumulação de capital é um processo cumulativo, ela induz o aprofundamento em segmentos com maior ganho de produtividade.

É importante fazer a ressalva que o incremento dos setores de trabalho é uma conjunção de queda do emprego com crescimento do VTI. Paralelamente, setores difusores estão crescendo a taxas menores do que o de recursos naturais. A conjunção desses fatores indica uma tendência à especialização em segmentos intensivos em recursos naturais e aprofundamento da heterogeneidade Ainda assim, esse processo não se mostra irreversível, uma vez que os setores difusores conseguiram manter crescimento em contexto desfavorável.

O segundo indicador analisado foi apresentado por Oliveira e Feijó (2011) e utiliza a relação entre o VTI e o VBPI para mostrar quanto da produção é intensiva em valor agregado gerado internamente. Como salientam os autores, essa medida deve ser vista como cautela, pois o peso dos custos industriais no valor da produção depende da taxa de câmbio. Como salientada acima, o período foi marcado por forte valorização cambial, parcialmente revertida apenas em 2016, ou seja, fora do escopo dos dados apresentados.

Mesmo com essas ressalvas decorrentes da influência de outros componentes no indicador, acreditamos que é importante analisar o comportamento do índice de agregação de valor como indicador complementar para a análise apresentada. $\mathrm{O}$ gráfico 3 apresenta os resultados para o período.

Gráfico 5 - Índice de Agregação de Valor (VTI/VBPI) - setores selecionados Brasil -2007-2015 - un.

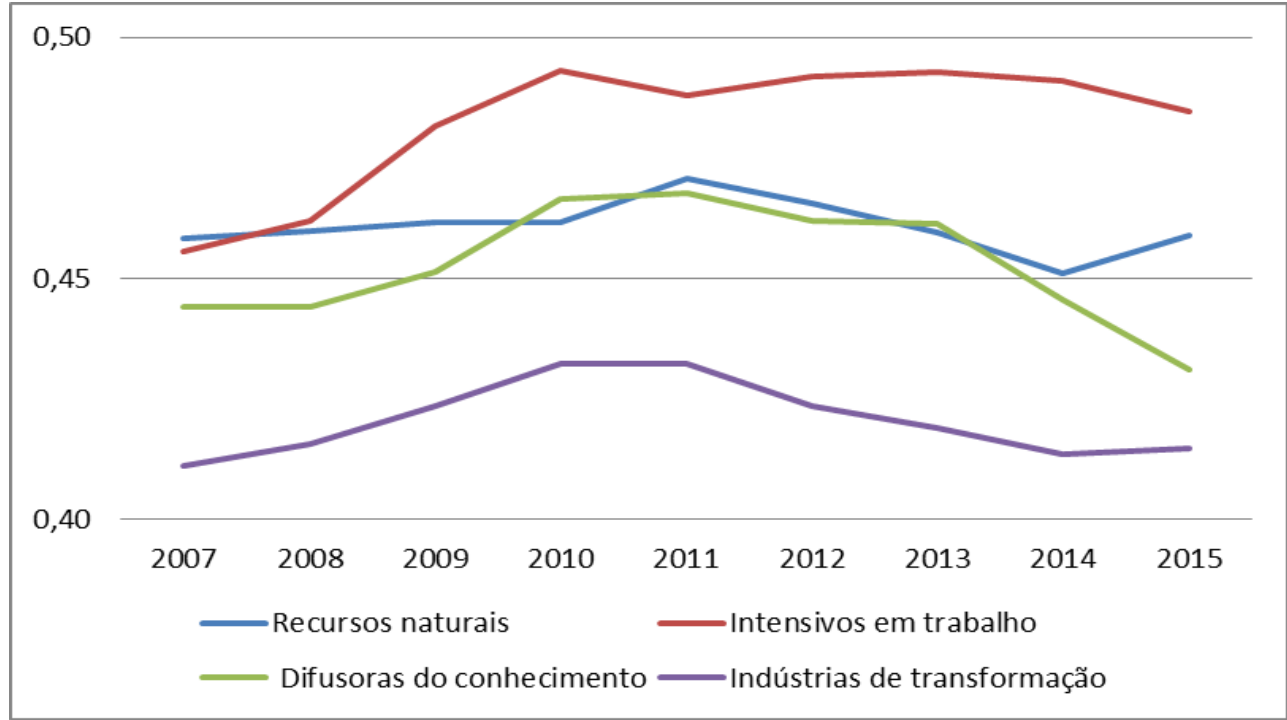

Fonte: Elaboração a partir da PIA 
Observa-se mais uma vez comportamento distinto entre os setores. Em primeiro lugar, os segmentos intensivos em trabalho mostram maior capacidade de agregar valor internamente com tendência crescente desde 2007 e início de reversão em 2015. Os setores difusores apresentaram uma trajetória positiva até 2010, que foi revertida e acentuada a partir de 2013. Os segmentos de recursos naturais foram menos voláteis no período. Ainda que sejam os setores com menor intensidade tecnológica, os intensivos em trabalho apresentam um indicador melhor.

Para complementar a análise do índice de geração de valor, apresentamos abaixo o coeficiente de penetração das importações, divulgado pela Confederação Nacional da Indústria $(\mathrm{CNI})^{7}$. O objetivo é avaliar o grau de dependência de importações em cada um dos setores.

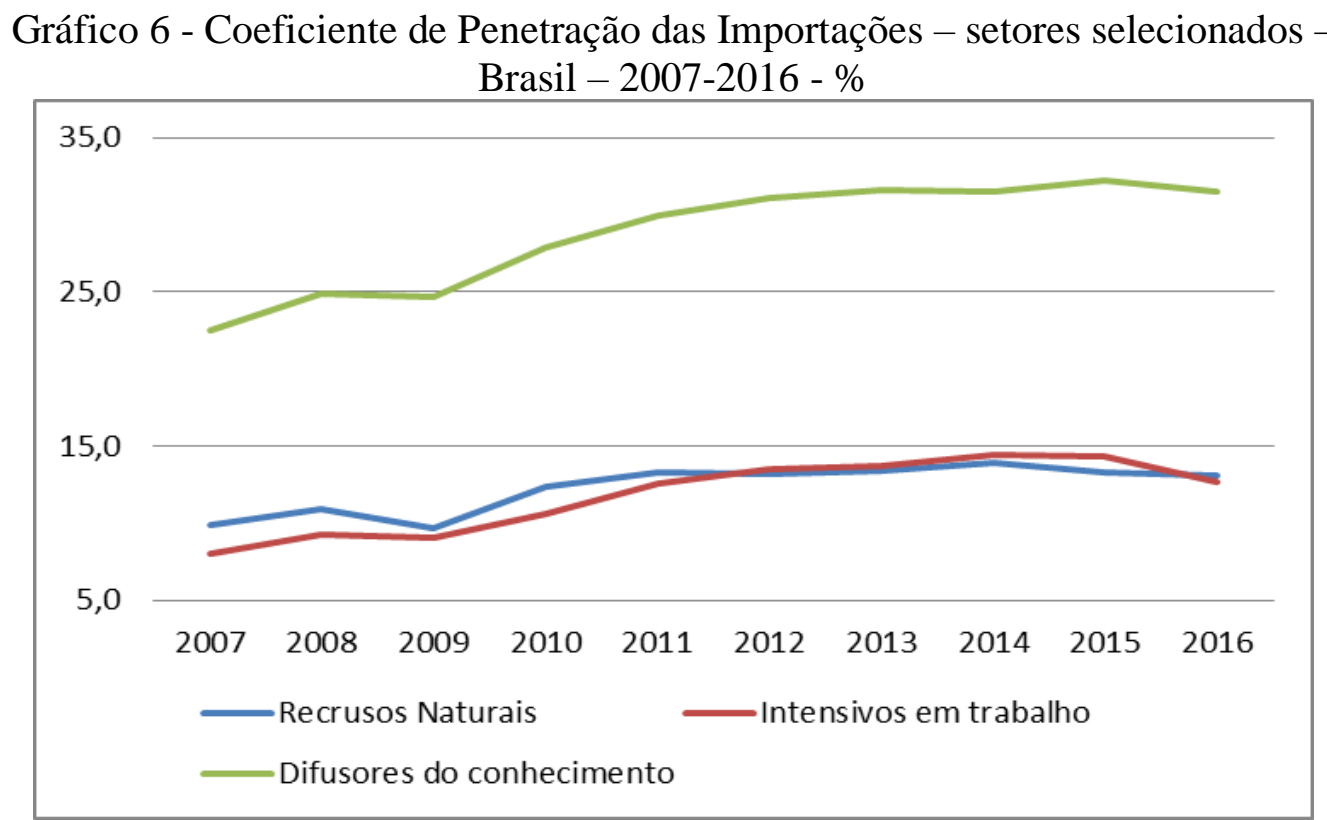

Fonte: Elaboração a partir de dados da CNI

Em primeiro lugar, fica clara a forte dependência dos setores difusores em relação às importações. Também é possível notar uma tendência ascendente para todos os setores, com crescimento mais expressivo dos intensivos em trabalho, reforçando a concepção de concorrência externa.

Considerando conjuntamente o índice de eficiência relativa e o coeficiente de penetração de importações, nota-se que o setor intensivo em trabalho apresenta forte capacidade de geração de valor internamente mesmo enfrentando concorrência externa. Por outro lado, os difusores tiveram um desempenho positivo até 2010 e começaram a declinar, o que coincide com o crescimento expressivo do coeficiente de penetração das importações. Por fim, para os recursos naturais, observa-se estabilidade tanto da capacidade de geração de valor quanto da participação das importações.

Avaliando conjuntamente o indicador de eficiência e o coeficiente de penetração das importações, observa-se que o incremento das importações foi acompanhado pela perda de capacidade de gerar valor internamente. Ainda que isso não represente uma relação de causalidade entre as variáveis, nota-se que as importações não se manifestaram como ganho de eficiência produtiva das empresas.

Para finalizar a análise a partir de dados da PIA, apresentamos alguns indicadores de custo. Em primeiro lugar, o custo unitário do trabalho, dado pela razão entre a massa salarial e o valor

\footnotetext{
${ }^{7}$ Importante salientar que quatro setores não apresentam dados: "produtos do fumo"; “impressão e reprodução de gravações"; "outros equipamentos de transporte" e "manutenção de máquinas e aparelhos".
} 
gerado na indústria (VTI). Quanto menor o indicador, menor a representatividade dos custos salariais. Em primeiro lugar, destaca-se que o período é marcado pela política de valorização de salários, que garantiu crescimento real do salário.

É importante analisar os resultados tendo em vista o comportamento dos dois elementos. Um processo virtuoso de crescimento ocorre mediante expansão das duas variáveis, o que denota aumento da produtividade e transferência desses ganhos aos salários. Uma variação positiva apenas do VTI indicaria que os ganhos de produtividade não se refletem em aumento do poder de compra dos trabalhadores ao passo que o crescimento apenas dos salários mostraria um padrão de compressão da margem de lucro que é insustentável para a viabilidade do setor. Crescimento do salário acima do aumento do VTI indica um processo de compressão dos lucros das firmas. $\mathrm{O}$ gráfico 3 apresenta os dados.

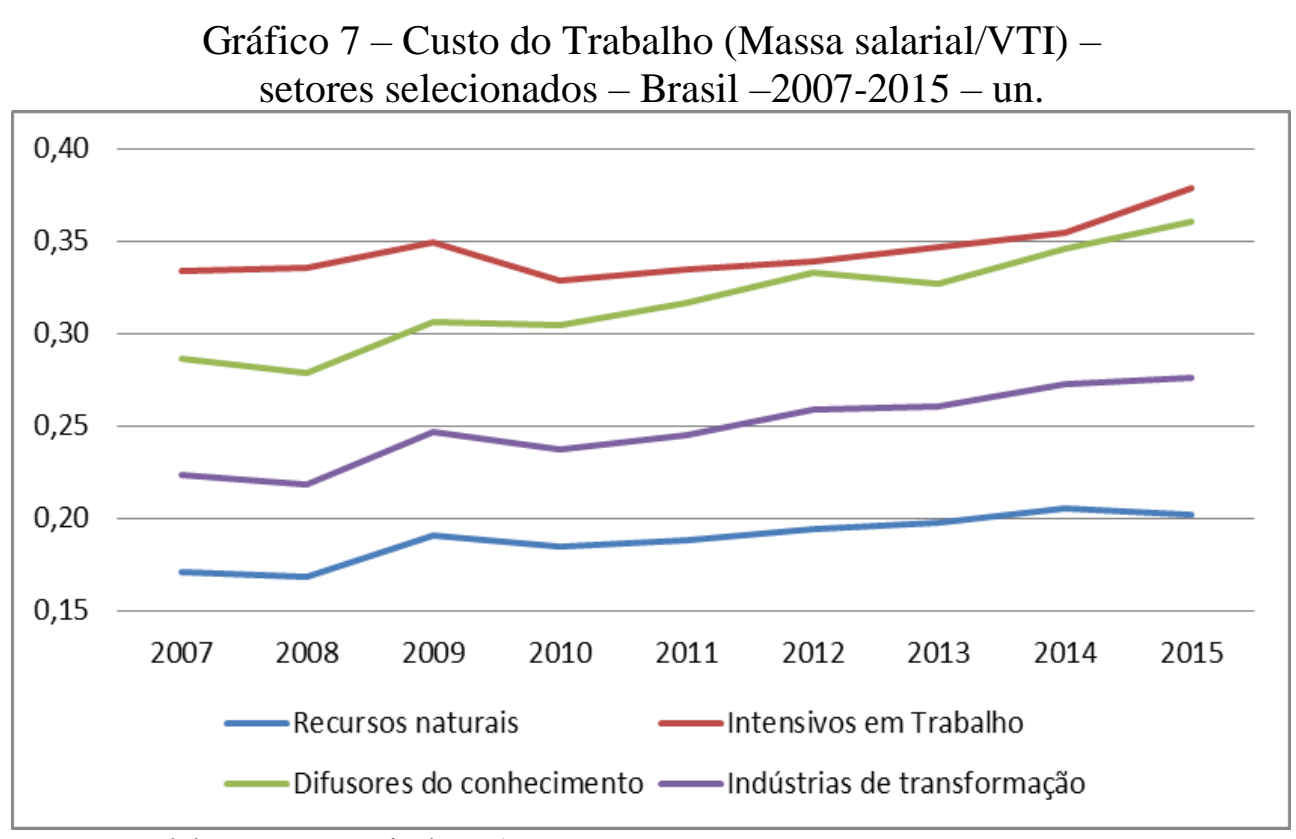

Fonte: Elaboração a partir da PIA

Fica clara forte discrepância entre os setores, com grande diferenciação do segmento de recursos naturais, reflexo do seu caráter capital intensivo. Para o período, o salário deste segmento aumentou $91 \%$ enquanto o VTI avançou $82 \%$. Paralelamente, observa-se uma convergência entre os difusores e os intensivos em trabalho, ambos com tendência ascendente. O aumento é explicado pelo crescimento mais expressivo dos salários (121\% para intensivos e $99 \%$ para difusores) em relação ao VTI (78\% e 49\%, respectivamente). O fraco crescimento do VTI para os difusores induz o processo de convergência mencionado.

Os dados mostram um processo de compressão das margens de lucro para a indústria e, em especial, para os setores difusores, que tiveram o menor crescimento do VTI para o período em questão, diminuído sua participação no VTI da indústria de transformação de $31 \%$ para $27 \%$. Assim como no indicador de produtividade do trabalho, mais uma vez destaca-se um processo de convergência entre os setores intensivos em trabalho e os difusores. Entretanto, também para esse indicador a convergência é fruto de um processo de perda de densidade industrial dos difusores.

Para complementar o panorama sobre as pressões de custos, finalizamos esta seção incorporando dados sobre custos das matérias-primas e das operações industriais. Os primeiros representam os gastos com os insumos da produção ao passo que o custo das operações industriais é dado pelos gastos relacionados diretamente com o processo produtivo. O objetivo é apresentar a magnitude desses gastos e identificar quais componentes têm maior peso do ponto de vista do processo produtivo. 
Gráfico 8 - Componentes dos custos - setores selecionados - Brasil - 2015 - Milhões R\$

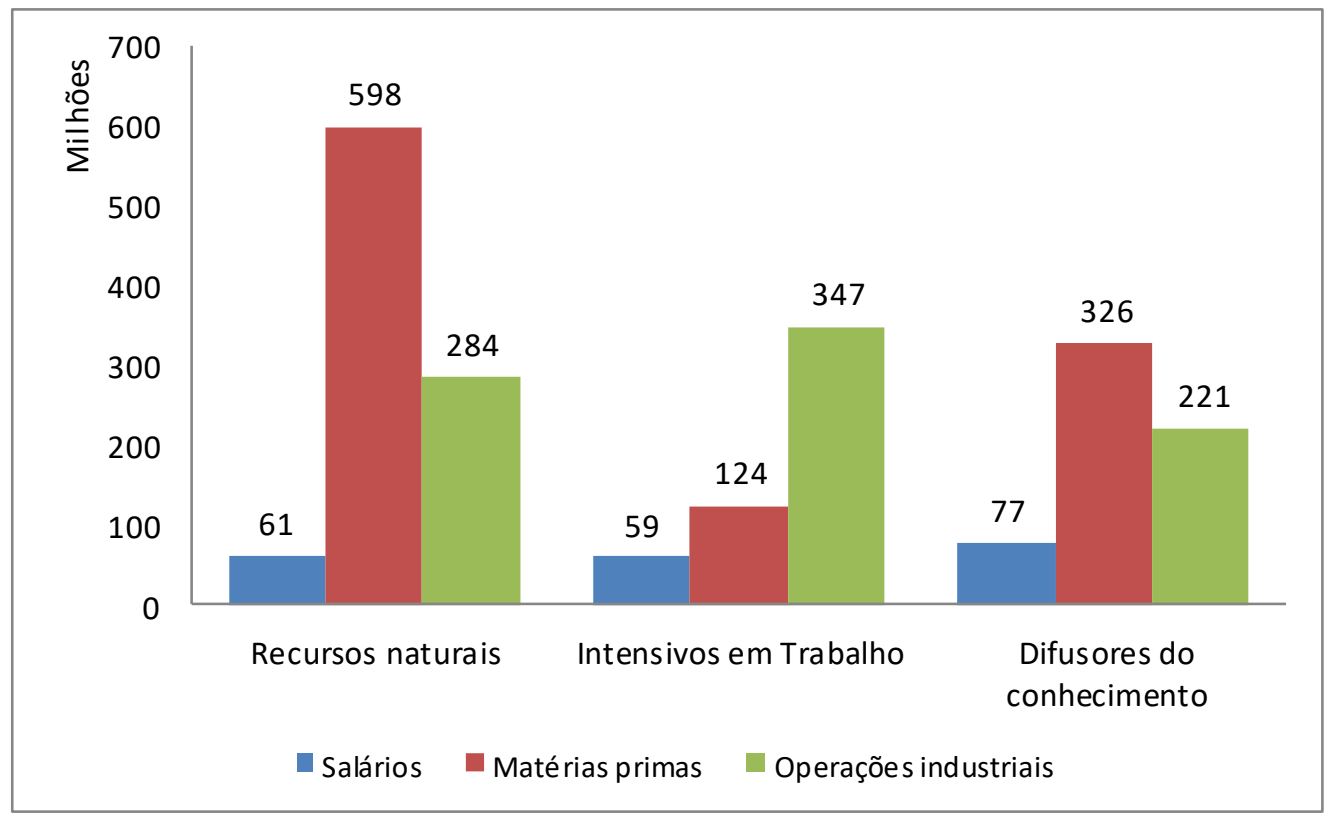

Fonte: Elaboração a partir da PIA

O gráfico mostra que os principais custos industriais estão relacionados à aquisição de matérias-primas para os recursos naturais e difusores, seguidos pelos custos das operações industriais. Para os setores intensivos em trabalho, o custo de operação é mais relevante que a matéria-prima. Esse fator pode ser uma decorrência da menor complexidade produtiva desses setores, que implica matérias-primas de menor valor agregado.

Para os três segmentos observa-se que os custos salariais têm o menor peso na composição de custos. Até mesmo para os setores intensivos em trabalho os gastos salariais não representam nem metade dos gastos com matérias-primas e menos ainda nas operações industriais. Adicionalmente, é importante destacar que entre 2007 e 2015 os custos salariais tiveram o maior crescimento, com variação média de $111 \%$ para a indústria de transformação, ao passo que os custos com operações industriais cresceram $68 \%$ e os custos relacionados às matérias-primas aumentaram $67 \%$.

Ou seja, mesmo com expansão significativa dos custos salariais, que dobraram no período, os custos com matérias-primas ainda se destacam como principal pressão para o setor industrial, seguidos pelos custos com operações industriais, que subiram expressivamente, principalmente devido ao crescimento do custo da energia. Sob a perspectiva dos custos, a matriz industrial tem nos insumos a maior pressão de custos, relativizando o crescimento salarial como principal pressão sobre a lucratividade da indústria.

\section{Considerações finais}

A partir do reconhecimento da especificidade do subdesenvolvimento, este trabalho buscou traçar um panorama dos setores difusores do conhecimento e sua relevância na indústria de transformação brasileira. Esse enfoque se deve ao fato de que as atividades industriais têm diferentes ritmos de crescimento da produtividade e apresentam graus diferenciados de encadeamentos produtivos, de modo que o estudo da estrutura produtiva se torna fundamental para compreender a dinâmica de acumulação de capital de uma economia. 
Para isso, utilizamos o corte metodológico com relação à capacidade de difundir inovações para outros setores da economia. Essa característica é fundamental tendo em vista a grande discrepância de produtividade observada em países subdesenvolvidos.

Para dimensionar esses aspectos na indústria de transformação brasileira, foram utilizados dados para avaliar indicadores de produtividade do trabalho, dos custos empresariais e de emprego. As análises foram feitas para todos os segmentos que compões a indústria de transformação e o comportamento agregado com o objetivo de identificar especificidades dos setores e tendências existentes. No que tange o emprego, apresentamos dados sobre o número total de trabalhadores, variação do salário real e a distribuição por faixas de remuneração.

Os dados de emprego vão até 2016 e mostram que a indústria de transformação teve crescimento menor que a economia como um todo, perdendo participação relativa. No âmbito setorial, é marcante a heterogeneidade do mercado de trabalho, tanto na distribuição de empregos quanto na remuneração. Houve crescimento mais expressivo dos setores de recursos naturais enquanto os outros segmentos tiveram retração, indicando um processo de especialização da indústria. Ainda assim, é importante destacar que mesmo com queda de $2,5 \%$ no número de trabalhadores, os difusores respondem por aproximadamente $25 \%$ do emprego industrial.

Com relação ao salário médio, os difusores apresentam o melhor resultado e o período foi marcado por convergência do salário na indústria. Entretanto, essa convergência é apenas parcial, na medida em que foi resultado do aumento relativo de um setor e retração dos demais.

Quanto à distribuição por faixa salarial, ainda predominam empregos com remuneração de até três salários mínimos, com mais de $70 \%$ do emprego industrial. Nesse quesito os segmentos difusores têm melhor distribuição, com $50 \%$ do emprego nessa faixa de remuneração. Além disso, a participação de empregos com maior remuneração é muito mais expressiva nesses segmentos. Os difusores respondem por mais de $40 \%$ dos trabalhadores industriais com remuneração acima de 10 salários mínimos.

Além do mercado de trabalho, este estudo também apresentou dados sobre a produtividade do trabalho na indústria. Mais uma vez fica clara a heterogeneidade que marca a estrutura produtiva. Os setores de recursos naturais apresentam produtividade muito superior aos outros segmentos e tiveram crescimento no período com avanço concomitante do VTI e do pessoal ocupado. Em contrapartida, os segmentos difusores e intensivos em trabalho tiveram aumento do VTI e queda no pessoal ocupado.

O indicador de eficiência relativa, mesmo com suas limitações, corrobora o panorama observado na produtividade do trabalho. Os resultados indicam que a estrutura produtiva nacional vem perdendo participação nos segmentos com maior potencial de geração de inovações intersetoriais. O ganho de densidade produtiva está se concentrando em segmentos com menor valor agregado e menor potencial de geração de inovações.

Isso mostra que a heterogeneidade produtiva vem se acentuando no período recente. Ademais, destaca-se que o aumento da produtividade nos difusores e nos intensivos em trabalho ocorreu mais devido à queda do emprego, ressaltando um perfil de crescimento perverso para a indústria e um padrão de baixa expansão da produtividade industrial.

Considerando que o período foi marcado por forte valorização do salário mínimo, apresentamos uma breve análise sobre a estrutura de custos dos setores para avaliar tendências. Primeiramente, o indicador de custo do trabalho, dado pela razão entre a massa salarial e o VTI mostra que o salário aumentou seu custo relativo no período.

Mesmo com forte crescimento do salário, que mais que dobrou no período, as matérias primas e os custos de operações industriais ainda representam a maior pressão sobre as empresas. Especificamente para os setores difusores, as matérias primas representam o maior componente de custo, com crescimento expressivo. 
Por um lado, isso relativiza o crescimento salarial como principal pressão sobre a lucratividade da indústria nacional. Por outro lado, mostra que os gargalos para a produção se concentram nas matérias-primas necessárias à transformação industrial.

Este estudo focou nos setores tecnologicamente dinâmicos devido à sua capacidade de difusão intersetorial das inovações. Tendo em vista que a estrutura produtiva dos países periféricos apresenta grande discrepância de produtividade, o estímulo direcionado pode contribuir para aumentar a produtividade da economia. Além disso, esses segmentos apresentam maior elasticidade-renda das exportações, o que contribui para reduzir a restrição externa que marca as economias periféricas.

Os resultados mostram que a participação dos setores difusores na matriz produtiva nacional é significativa, mas apresentou uma dinâmica perversa no período recente, com retração do emprego e menor crescimento tanto do VTI quanto da produtividade. Mesmo nesse contexto adverso, os setores se mostraram resilientes tendo em vista a retração da indústria como um todo.

Com relação aos benefícios fiscais concedidos no período, este trabalho não se propõe a avaliar os impactos de tais medidas, mas dada a abrangência dos setores beneficiados, é difícil caracterizá-los como uma política industrial direcionada. Na inexistência de um contra factual para avaliar o impacto das medidas, fica claro que os incentivos, no máximo, contribuíram para atenuar a perda de densidade industrial do tecido produtivo. Destaca-se que uma política efetiva para o desenvolvimento do setor deve ser direcionada especificamente para os setores difusores de conhecimento, o que possibilitaria uma dispersão dos ganhos de produtividade para outros setores.

É importante ressaltar que este trabalho constitui o primeiro passo de uma agenda mais ampla de pesquisa sobre o desempenho industrial. Após esse diagnóstico inicial, é importante avaliar o tamanho da brecha tecnológica em âmbito internacional para dimensionar o esforço necessário para viabilizar o catch-up com as economias centrais. Paralelamente, uma análise de inserção externa é capaz de mostrar como os setores reagiram às mudanças no comércio internacional, notadamente da variação cambial no período.

\section{Referências Bibliográficas}

AFONSO, J. R.; PINTO, V. C. Composição da desoneração (completa) da folha de salários. Texto para Discussão n.41 IBRE-FGV 2014

ALCORTA, L. The Impact of New Technologies on Scale in Manufacturing Industries: Issues and Evidence. World Development. Vol. 22, No. 5, pp. 755-769. 1994

BRITTO, J. Mudança estrutural, produtividade e investimento na indústria Brasileira: uma abordagem intersetorial no período 96-10. In: XVIII ENCONTRO NACIONAL DE ECONOMIA POLÍTICA, Anais do Encontro Nacional de Economia Política. 2013

CANO, W. Desconcentração produtiva regional do Brasil 1970 - 2005. São Paulo: Editora UNESP, 2008

CARVALHO, L. Valsa Brasileira: Do boom ao caos econômico. Todavia, São Paulo. 2018

CARVALHO, L; KUPFER, D. A transição estrutural da indústria brasileira: da diversificação para a especialização. In: $35^{\circ}$ ENCONTRO NACIONAL DE ECONOMIA. Anais do Encontro Nacional de Economia. 2007 
CIMOLI, M. PORCILE, G, PRIMI, A., VERGARA, S. Cambio estructural, heterogeneidad productiva y tecnologia em America Latina. In: Porcile, G. Heterogeneidad estrutural, asimetrias tecnológicas y crecimiento em America Latina. 2005

DOSI, G. Technical change and industrial transformation. New York, USA: Martin's Press 1984

DOSI, G; PAVITT, K. SOETE, L. Economics of technical change and international trade. Nova York, Penguins, 1990

FAJNZYLBER, F. A empresa internacional no processo de industrialização da América Latina. In: SERRA, J. América Latina: ensaios de interpretação econômica. São Paulo: Paz e Terra. 1976

FEIJÓ, C. A.; LAMONICA, M. T . A kaldorian approach to catch-up and structural change in economies with a high degree of heterogeneity PSL Quarterly review, vol. 66, n 265, 107-135. 2013, 2007

FURTADO, C. Desenvolvimento e subdesenvolvimento. Rio de Janeiro: Fundo de Cultura. 1961

GOUVÊA, R. R.; LIMA, G. T. Mudança estrutural e crescimento sob restrição externa na economia brasileira: 1962-2006. Economia e Sociedade. Campinas, vol. 22, n¹, Abril 2013

GRAMKOW, C. Heterogeneidade estrutural e da inserção externa no Brasil: uma análise empírica para o período de 1990 a 2008. Desindustrialização e especialização tecnológica: uma análise empírica entre 1989-2010. In: 39 ENCONTRO NACIONAL DE ECONOMIA, 2011. Anais do Encontro Nacional de Economia. 2011

HOLAND, M., PORCILE,G. Brecha tecnológica y crecimiento en América Latina. In: Porcile, G. Heterogeneidad estrutural, asimetrias tecnológicas y crecimiento em America Latina. 2005

JAYME JR, F. G.; RESENDE, M. F. C. Crescimento Econômico e Restrição Externa: teoria e a experiência brasileira. In: Renault Michel; Leonardo Mello. (Org.). Crescimento Econômico: Setor Externo e Inflação. 1 ed. Brasília: IPEA, v. 1, p. 25-45. 2009

MALERBA, F.; NELSON, R. Learning and catching up in different sectoral systems: evidence from six industries. Industrial and Corporate Change, V. 20. $\mathrm{N}^{\circ} 6.2011$

LALL, S. The technological structure and performance of developing country manufactured exports, 1985-1998. Oxford Development Studies, v. 28, n. 3, p. 337-369, 2000.

LAMONICA, M. T.; FEIJÓ, C. A. Crescimento e Industrialização no Brasil: As lições da lei de Kaldor. In: $35^{\circ}$ ENCONTRO NACIONAL DE ECONOMIA. 2007 Anais do Encontro Nacional de Economia. 2007

OLIVEIRA, F. A economia brasileira: crítica à razão dualista. 4 ed. Petropólis, RJ: 1981 .

OLIVEIRA, D. R; FEIJÓ, C. A. V. C . Mudanças estruturais na economia brasileira e seus impactos sobre a evolução da produtividade na indústria de transformação pós-1990. 2011 
PAVITT, K. Sectoral patterns of technical change: towards a taxonomy and a theory. Research Policy, 13, 343-373 1984

PINTO, A. Natureza e implicações da 'heterogeneidade estrutural' na América Latina. In: BIELSCHOWSKY, R. (org.) Cinquenta anos de pensamento na CEPAL. vol. II. Rio de Janeiro, Cofecon-Cepal; Record, 2000

PORCILE, G.; HOLLAND, M.; CIMOLI, M.; ROSAS,L. Especialización tecnologia y crecimiento en el modelo Ricardiano. 2010

RODRIGUEZ, O. O Estruturalismo Latino Americano, Rio de Janeiro. Civilização Brasileira. 2009 